\title{
NOISE DETECTION SYSTEM
}

\author{
Shaikh Shahrukh \\ Department of IT, \\ A.C Patil College of Engineering, \\ Mumbai, Maharashtra, India
}

\author{
Mulani Rameez \\ Department of IT \\ A.C.Patil College of Engineering, \\ Mumbai, Maharashtra, India
}

\author{
Khan Abdul \\ Department of IT \\ A.C. Patil College of \\ Engineering, Mumbai, \\ Maharashtra, India
}

\begin{abstract}
Noise Pollution is a growing problem in Modern cities, thanks to rapid population growth, urbanization and new technologies. Moreover, at times, a noisy neighbor or co-worker can drive you crazy and affect your wellbeing. Traffic light control systems ar widely used to monitor and control the flow of automobiles through the junction of many roads. They aim to realize smooth motion of cars in the transportation routes. However, this system also leads to Noise Pollution which this present traffic signal doesn't considers a problem. But any sound which crosses the parameter of $90 \mathrm{~Hz}$ is considered Noise which you'll get to hear at each and every traffic signal present at every adjacent intersection. Exposure to prolonged or excessive noise has been shown to cause range of health problems ranging from stress, poor concentration, productivity loss in the workplace, and communication difficulties and fatigue from lack of sleep, to more serious issues such as cardiovascular disease, cognitive impairment, tinnitus and hearing loss. Hence, to overcome all these problems and help our society we propose a system based on Arduino with High-end microphone sensors and our algorithm to detect and distinguish between Normal sound and Noise based on that decision Vehicle riders present at that traffic signal will be penalized with extra time to spend on that junction
\end{abstract}

Keywords - Noise Detection, Noise Pollution, Noise Management.

\section{INTRODUCTION}

All these modern technologies just make people try to do everything at once. Nowadays, people tend to be busier; and because of this, people tend to forger also some of their responsibilities which are the main cause of trouble. One of these responsibilities is having to maintain decorum of the environment as per your surroundings. Environmental noise, defined as unwanted or harmful outdoor sound created by human activities, can be generated by traffic, industry, construction and recreation activities, Airports, Power plants, Shooting-ranges and Motorsport tracks are examples of Noise sources for which Sound Propagation is over several Kilometers is relevant.
But today our aim is to eliminate Noise near traffic signal by installing our system in already available Traffic signals which will ultimately upgrade our old traditional traffic signals.

What our system will do is:

1. Will work as a traditional traffic signal.

2. But when it shows red signals to drivers and if Honking is detected instead of giving a clean chit to drivers and let them go it'll penalize them by restarting timer for red signal.

We group members of this project i.e. Shahrukh Shaikh, Rameez Mulani and Abdul Khan got motivation for this project when we decided to make a project which will bring a great impact on our society while helping our society. Our goal was to accomplish to aims which was to help our society and make a great impact on society with our project. After a long-term research, we got into Noise Pollution and hence we ended up with our current project which aims to reduce noise pollution in the vicinity of traffic signals which will also help in the flow of traffic at junctions.

\section{BACKGROUND}

Noise is widely known in science and technology. Its general meaning in such fields, as in everyday life, is useless or interfering signal of some form. It is any unwanted sound due to a variety of causes. Often, noise is a nuisance because it interference with a measurement that it is being made or with some signal that is being transmitted. Noise levels are usually measured in decibel unit. A decibel is one tenth of a bel (B). Devised by engineers of the Bell Telephone Laboratory to quantify the reduction in audio level over a 1 mile $(1.6 \mathrm{~km})$ length of standard telephone cable.

The system uses Microphones and Arduino board with our Algorithm in order to determine and distinguish between normal sound and Noise. The device aims to detect excessive noise in the vicinity of traffic signals and also ensure free flow of traffic at junctions. The following points were considered in order to implement the design project:

1. To be able to lessen the noise in the vicinity of Traffic signal. 


\section{International Journal of Engineering Applied Sciences and Technology, 2021 \\ Vol. 6, Issue 1, ISSN No. 2455-2143, Pages 106-116 \\ Published Online May 2021 in IJEAST (http://www.ijeast.com)}

2. To be able to penalize the riders that cause Noise near Traffic signal.

3. To design an effective and efficient device for the use of Traffic Department.

\section{LITERATURE SURVEY}

Adiraek Siamwala, Zac Lochhead and Waleed Abdulla [1] designed a device which could Monitor Environmental noise using Distributed IoT Sensor Nodes. In this project Common issues associated with wireless sensor networks for analyzing environmental noise include high power usage, high cost, and limited scalability are addressed.

Yung-Chung Tsao, Bo-Rui Su, Chin-Tan Lee, Chia-Chun $\mathrm{Wu}$ [2] had implemented a distributed sound sensing system to visualize the noise pollution. The aim of this study is to implement a portable, small-scale and internet-based sounddetective prototype by using Internet of Thing (IoT) technology to offer a better solution mentioned above. So our approaches are that we use the cheaper materials and lowprecision sensor and single-chip microcomputer (MCU) with WIFI connection ability to develop a dedicated sounddetective device.

Udit Satija, Barathram Ramkumar, M. Sabarimalai [3] had implemented a system which was capable of automated detection and classification of ECG Noise for Unsupervised Healthcare Monitoring. In the proposed framework, ECG signals are first decomposed using the modified CEEMD algorithm for discriminating the ECG components from the noises and artifacts.

Alain Dufaux, Laurent Besacier, Michael Ansorge and Fausto Pellandini [4] had deviced a system which can automatically detect and recognize whether an environment is noisy or not. This paper addresses the problem of automatic detection and recognition of impulsive sounds, such as glass breaks, human screams, gunshots, explosions or door slams.

\section{METHODOLOGY}

This is how our proposed system will work, the main function of our system starts after it shows a red light in traffic signal. Once it shows a red light our proposed system with all its Sensors and algorithm starts listening to the sound available in the vicinity and if any noise is detected in the vicinity the Noise detection system will penalize the vehicle riders on the traffic signal by restarting the timer for red signal.
Block diagram:

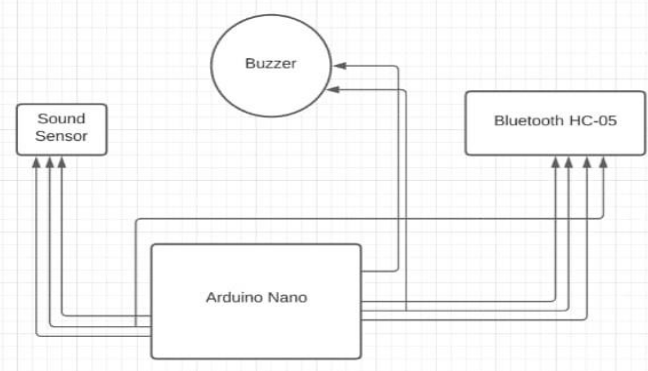

Fig 1: Block Diagram

\section{DESIGN AND IMPLEMENTATION}

This section discusses the system modelling, process and theoretical design of the Noise Detection System. It also describes the flow of instructions.

Multiple Sensor Array \& Structure of the Noise Detection System: The Noise Detection System utilizes numerous sensors to detect noise in the vicinity where it's installed. These are the components of the Noise Detection System Power Supply, Arduino Nano, Bluetooth Sensor, Sound Sensor, Buzzer/Vibration Motor. This multisensory system makes surveillance at traffic signal more effective and also penalizes Vehicle riders which unnecessarily honk at traffic signal. Moving on to the structure of the SPR, The Noise detection system is made using Box of mobile phone which is durable and strong which can withstand hits to some extent and is quite portable and is quite easy to install aside a Traffic signal. Since it has to be installed aside a Traffic signal, this system is made very lightweight; about $400 \mathrm{~g}$ and it is also quite small in size, $15 \mathrm{~cm} \times 15 \mathrm{~cm} \times 10 \mathrm{~cm}$. It contains multiple sensors which help the system in detecting noise and penalizing vehicle riders. section.

Hardware Implementation: The SPR has the shape of a fourwheeler, and it is equipped with Power Supply, Rectifier, Regulator, Night Vision Camera, Servo Motor, Motor Driver, Motor, WIFI Module, Sound Sensor, Ultrasonic sensor, Raspberry Pi. Raspberry pi is installed with the night vision camera which help the system to go for the automation and help to find the human or any problem detected using the sound sensor and according to the sound produced it automatically goes to that area and capture the image and send it to user using IOT technology. 


\section{International Journal of Engineering Applied Sciences and Technology, 2021 \\ Vol. 6, Issue 1, ISSN No. 2455-2143, Pages 138-140 \\ Published Online May 2021 in IJEAST (http://www.ijeast.com)}

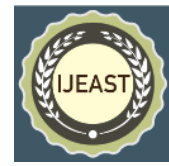

Fig 3: Noise Detection System (Top View)

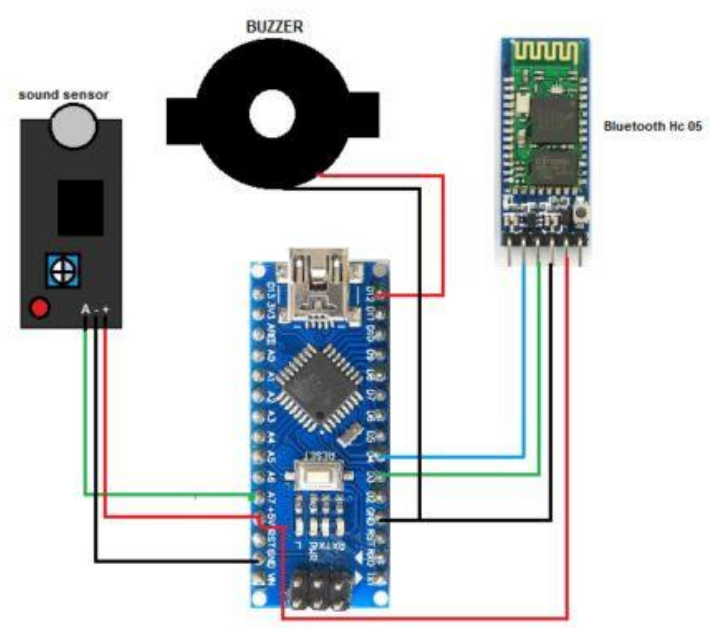

Fig 2: Circuit Diagram

Working: The Noise Detection System first and foremost functions as a tradition traffic signal, the main functions of the system starts when it detects noise in the vicinity of the traffic signal, once it detects some sound using High-end microphone sensors it will take the due course according to the protocols provided by user i.e. Rather than keep functioning as a normal traffic signal it will penalize the vehicle riders by restarting the timer of the Traffic signal.

\section{RESULT}

Our proposed system attempts to make practical model of Noise Detection based system which not only just detects noise but also is capable of distinguishing between normal sound and noise on the basis of intensity of sound and based on that comparison it makes decision to penalize vehicle riders in the vicinity of Traffic signal. The advantage of this project is that it won't just help in reducing sound in vicinity of Traffic signal but also help in smoothening Traffic and also force vehicle riders to not honk unnecessarily at traffic signals.

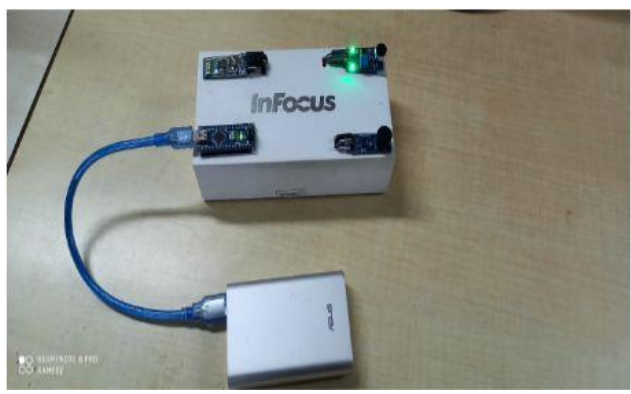

\section{ACKNOWLEDGEMENT}

It is indeed a matter of great pleasure and proud privilege to be able to present a paper on "Noise Detection System". This manuscript would have not been possible without the go ahead from our respected principal Dr. V. N. Pawar. We would like to express our gratitude to our H.O.D (I.T.) Prof. Supriya Joshi for allowing easy access to all the facilities so liberally and encouraging us. We are heartily thankful to our project guide Prof. Amol Patil whose encouragement, guidance and support from initial level to final level enabled us to prepare this report. Lastly, we offer our regards to all those who supported us in any respect during the completion of this report. Any suggestion or criticism for this report will be highly acknowledged.

\section{REFERENCES}

[1] A. Siamwala, Z. Lochhead and W. Abdulla. (2019). Environmental Noise Monitoring Using Distributed IoT Sensor Nodes; 2019 International Conference on Electronics, Information and Communication (ICEIC), 2019, pp. 1-10, DOI: 10.23919/ELINFOCOM.2019.8706473.

[2] Y. Tsao, B. Su, C. Lee and C. Wu. (2017). An implementation of a distributed sound sensing system to visualize the noise pollution; 2017 International Conference on Applied System Innovation (ICASI), 2017, pp. 625-628, DOI: 10.1109/ICASI.2017.7988503.

[3] U. Satija, B. Ramkumar and M. S. Manikandan. (2017), Automated ECG Noise Detection and Classification System for Unsupervised Healthcare Monitoring; in IEEE Journal of Biomedical and Health Informatics, vol. 22, no. 3, pp. 722732, May 2018, DOI: 10.1109/JBHI.2017.2686436.

[4] A. Dufaux, L. Besacier, M. Ansorge and F. Pellandini. (2017). Automatic sound detection and recognition for noisy environment; 2000 10th European Signal Processing Conference, 2000, pp.1-4. 